\title{
Skin Health Connected to the Use of Absorbent Hygiene Products: A Review
}

Johanna Karlsson Bender • Jan Faergemann •

Maria Sköld (D)

Received: May 2, 2017 / Published online: June 30, 2017

(c) The Author(s) 2017. This article is an open access publication

\section{ABSTRACT}

Over the past 50 years, absorbent hygiene products such as baby diapers and incontinence products have become essential features of modern day life. Through innovation and enhanced technology, their design, composition and performance have been dramatically upgraded from their early forms, and they have transformed the lives of millions of people, improving their quality of life. Skin health related to the use of absorbent hygiene products has accordingly also greatly improved. Still, the wearing of absorbent hygiene products will affect the skin, and for some users the changes in microclimate, mechanical interactions and the exposure to urine and faeces may result in irritant contact dermatitis, i.e. diaper dermatitis (DD) or incontinence-associated dermatitis (IAD). Babies with developing skin and the elderly with deteriorating skin functions who are the most frequent users of absorbent hygiene products are more vulnerable to the

Enhanced content To view enhanced content for this article go to http://www.medengine.com/Redeem/ 1D98F060197E6D69.

J. K. Bender · M. Sköld ( $₫)$

SCA Hygiene Products AB, Göteborg, Sweden

e-mail: maria.skold@sca.com

J. Faergemann

Department of Dermatology, Sahlgrenska University

Hospital, Göteborg, Sweden causal factors. Although irritant reactions are the most common, allergic contact dermatitis should be considered if a DD/IAD fails to improve by recommended actions. There is also a connection between IAD and pressure ulcer development of which it is important to be aware. A holistic approach of using high-quality absorbent hygiene products in combination with appropriate skin care will help maintaining good skin health.

Keywords: Absorbent hygiene product; Diaper dermatitis; Incontinence associated dermatitis; $\mathrm{pH}$; Skin barrier; Skin health; Stratum corneum

\section{INTRODUCTION}

The emergence of disposable absorbent hygiene products, for, e.g., babies and people suffering from incontinence, has transformed the lives of millions of people whether they are users of the products or people who care for them. The absorbent hygiene products contribute to improved quality of life by attributes of dryness, hygiene, leakage control, comfort, and skin health. Incontinence products have a significant positive impact on the quality of life of individuals suffering from incontinence, by offering security, comfort, discretion and odour control. They also enable users to maintain their sense of dignity and engender the 
confidence that allows them to leave their homes, work, take part in social activities and lead a full and satisfying life.

Absorbent hygiene products are worn in close contact with the skin and accordingly they interact with the skin. Urine and faeces, contained in the products, may also come in contact with, and interact with, the skin. The skin of a healthy adult is a good, protective barrier but repeated exposure to, e.g., urine, faeces and excessive moisture may weaken the skin barrier. The resulting skin irritation is called diaper dermatitis (DD) or incontinence-associated dermatitis (IAD). The young and old users of those products also have a skin that is under development or where many skin functions have deteriorated, increasing the demand on the absorbent hygiene products and the skin care in that region of the body, in order to minimize the negative skin impact.

This review article is based on previously conducted studies and does not involve any new studies of human or animal subjects performed by any of the authors.

\section{PROGRESS IN PRODUCT DEVELOPMENT OF DISPOSABLE ABSORBENT HYGIENE PRODUCTS}

The first disposable baby diaper was produced around the 1940s and was a product that consisted of squares of soft crepe paper folded into a rectangular shape and held in place by a plastic pant. Since then, there have been a number of improvements in design and function, and today's diapers are often incredibly effective as regards both absorption and dryness. The introduction of superabsorbent polymers in the absorbent disposable hygiene products in the middle of the 1980s was a very important milestone for improving the skin health of the users. The presence of the superabsorbent polymers in the absorbent hygiene product allow for better absorption of liquid, and since the polymers lock the liquid inside, the contact between liquid and skin is minimized, which results in a healthier skin [1-3].

Complete and prolonged occlusion of skin will with time result in a higher humidity, $\mathrm{pH}$ and microbial growth [4] in the area that is covered by the product. Therefore, the introduction of water-vapour-permeable materials (also called "breathable" materials) was yet another step in improving skin health for the users, helping to reduce the humidity in the microclimate $[5,6]$ and skin hydration [5]. As shown by Fig. 1, the frequency of diaper dermatitis in infants has accordingly decreased over the years, and it appears that better disposable diaper technologies have played a key role in the improvement of skin condition [7].

\section{THE SKIN BARRIER}

The main function of the skin is as a barrier between the body and the environment [8]. It serves to protect the body from hazardous external factors like chemicals and colonizing microorganisms, while at the same time keeping the internal system intact, thereby upholding the balanced and strictly controlled physiological conditions needed for life (i.e. water homeostasis).

The skin is composed of three distinct layers: the epidermis, dermis and subcutis. Epidermis is a multilayered self-renewing keratinized epithelium and is the part of the skin that is in contact with the external environment. The skin barrier function resides in the epidermis, or, to be more specific, in the stratum corneum (SC), the outermost part of epidermis. SC is normally 10-20 $\mu \mathrm{m}$ thick, but, despite its thinness, it is a structure with remarkable properties. It consists of 10-25 layers [9] of flat, partly overlapping keratin (protein)-filled cells: corneocytes, organized approximately in parallel to the skin surface, and surrounded by a highly organized lipid matrix [10,11]. The structural arrangement of SC is often envisaged as a brick wall, where the corneocytes correspond to the bricks and the surrounding lipid matrix to the mortar [12].

The corneocytes are more or less impermeable for all penetrants, with water molecules as an exception [13]. The barrier capacity of the skin is therefore said to be a function of the molecular architecture of the lipid structure in the extracellular space of the SC [14]. The three 
Product Innovation and Diaper Rash Reduction

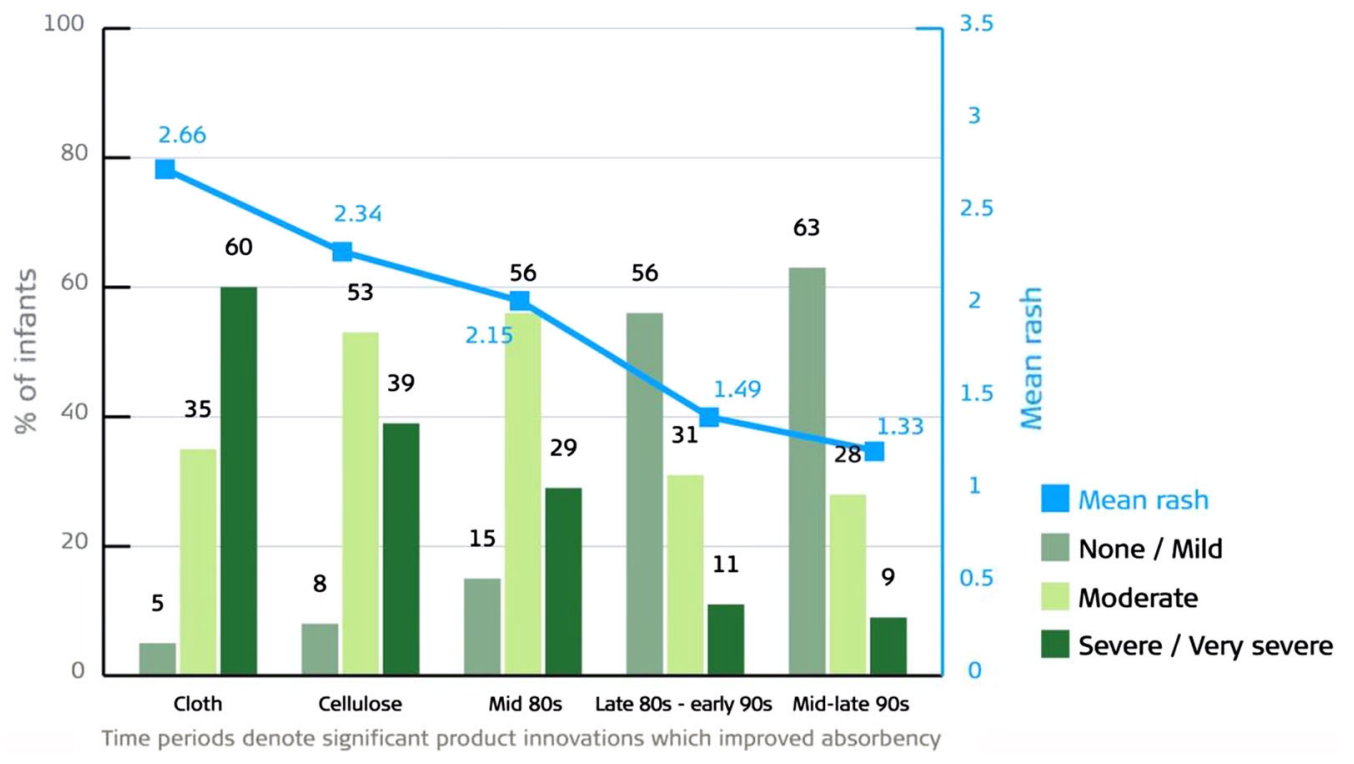

Fig. 1 Effect on frequency of diaper dermatitis from development of modern disposable diapers [7]

major lipid classes of the human SC are ceramides, free fatty acids and cholesterol, which are present in an almost equimolar ratio [15]. However, their precise molecular organization is still not solved, even if time and the development of new methodological approaches have taken the solution closer $[8,14,16]$.

The structural organization of the corneocytes and the lipid matrix of SC are of utmost importance for the barrier function, but equally important is that the layer is renewed [17]. As mentioned earlier, epidermis is a self-renewing structure in which corneocytes are released from the skin surface in a continuous and controlled way, and this process (desquamation) is strictly balanced towards the production of new cells in the deepest part of viable epidermis in order to uphold the barrier function of the SC.

\section{SKIN SURFACE PH}

Stratum corneum $\mathrm{pH}$ is relatively acidic compared to the body's near neutral, internal environment. Skin surface $\mathrm{pH}$ varies between different body sites and between different persons, but ranges approximately between 4 and 6 . Thus, there is a difference of $2-3 \mathrm{pH}$ units, or a factor of 100-1000 in proton concentration, between the living part of the epidermis and the skin surface [18]. The acidic $\mathrm{pH}$ has been shown to be important for barrier homeostasis, SC integrity and cohesion [19], and pro-inflammatory cytokine signaling [20]. Several pH-dependent enzymes are involved in the formation of the SC barrier, especially the hydrophobic barrier lipids, as well as its destruction by desquamation. The enzymes involved in the synthesis of barrier lipids have their optima at relatively low $\mathrm{pH}$, e.g. $\beta$-glucocerebrosidase, which is involved in the synthesis of the ceramides, has a $\mathrm{pH}$ optimum of 5.6. In contrast, the enzymes involved in the degradation of the skin barrier have their optima at a higher $\mathrm{pH}$, e.g. alkaline ceramidase, responsible for the degradation of barrier lipids, has a $\mathrm{pH}$ optimum of 9 [18]. So, a raised skin $\mathrm{pH}$ will alter the homeostasis by increasing the activity of enzymes involved in the degradation of the skin barrier, and by decreasing the activity of enzymes involved in the synthesis and processing of the barrier lipids [21].

SC $\mathrm{pH}$ is also important for the skin's antimicrobial properties. The growth of the normal skin flora is optimal at acidic $\mathrm{pH}$ levels, whereas pathogenic bacteria, such as $S$. aureus, 
thrive at neutral $\mathrm{pH}$ levels [19]. In general, higher bacterial counts are retrieved from skin with alkaline $\mathrm{pH}$ values [22].

It has long been recognized that age is a factor which influences skin $\mathrm{pH}$. Immediately after birth, skin surface $\mathrm{pH}$ is elevated compared to older children and adults. The $\mathrm{pH}$ decreases during the first days of life to about 5.5, and the $\mathrm{pH}$ value later in infancy resembles those of adults $[18,19]$. At the other end of life, an increased skin surface $\mathrm{pH}$ and a reduced buffer capacity in skin of the elderly have been seen. An increased sensitivity to skin irritants, cleansing procedures and bacterial infections is a result of the reduced alkaline neutralization capacity in older individuals. The activity of alkaline ceramidase has been found to be higher in aged human skin, which could explain the ceramide deficiency observed in the elderly $[18,19]$.

\section{DIAPER DERMATITIS AND INCONTINENCE-ASSOCIATED DERMATITIS}

DD is one of the most common skin conditions in infants and it has been reviewed in a number of publications [23-26]. It is an irritant contact dermatitis (ICD), which is an inflammation of the skin in the area covered by the diaper. IAD is a similar condition affecting older, incontinent persons wearing absorbent incontinence products. IAD has also been described and reviewed in many publications [27-30]. In both conditions, the somewhat humid environment under the diaper/absorbent incontinence product makes the skin more susceptible to injury from exposure to irritants, such as urine and faeces, and by friction from the materials of the product. The prevalence of both DD and IAD has in several studies been seen to vary widely $[26,27,31-33]$. The great variation could be due to different nature of studies, the product used and to different study populations, e.g. in regard of age and urinary/faecal incontinence (for IAD).

The reason for the increased vulnerability of the skin in the diaper area is multi-factorial, where one factor often leads to, or is aggravated by, another $[26,28]$. The occlusive environment created by the absorbent product (depending on, e.g., the breathability of the product) changes the microclimate close to the skin (higher humidity and temperature) which in turn affects the skin with a rise in humidity, $\mathrm{pH}$ and temperature. The skin also becomes affected mechanically by the product, and wet skin is more vulnerable to mechanical interaction. There may also be irritants, microorganisms and enzymes from urine and faeces which have a negative impact on the skin (Fig. 2). All these factors together break down the skin barrier and the skin responds with inflammation, through the release of cytokines (e.g. IL-1 $\alpha$ ) resulting in an immune response, giving the symptoms of dermatitis; erythema, oedema, itching and sometimes pain. Microorganisms play an important role in DD and, when the barrier is weakened microorganisms normally present in the perineum area, may give rise to infection (Table 1) [34].

In a study by Stamatas et al. [35], non-invasive in vivo methods were used to document biophysical skin parameters characterizing the conditions of DD. They found a significant increase in skin erythema and hydration and a significant impairment in the SC water barrier on DD-involved areas compared to non-compromised skin within and outside the diapered area. Skin $\mathrm{pH}$ was also significantly more alkaline on affected skin sites but also on non-lesional diapered skin compared to non-diapered control sites.

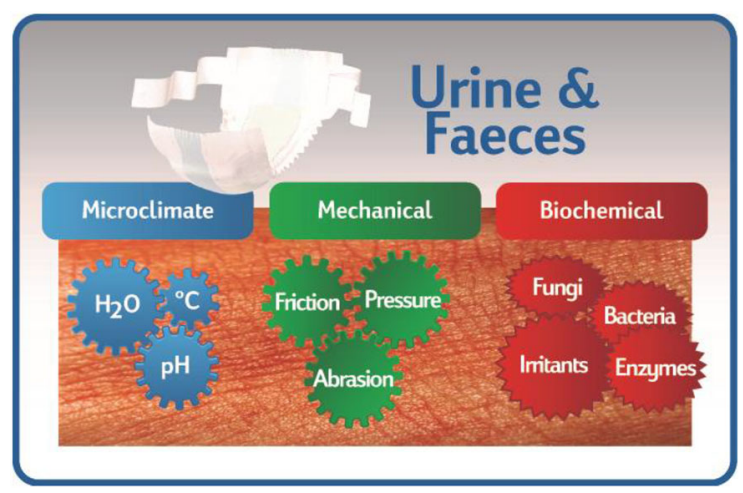

Fig. 2 External factors causing diaper dermatitis and incontinence-associated dermatitis 
Table 1 The skin microflora in perineum [34]

\begin{tabular}{ll}
\hline Microorganism & Percentage \\
\hline Coagulase-negative staphylococci & 97 \\
Lactobacilli & 97 \\
Corynebacterium spp. & 92 \\
Escherichia coli & 47 \\
Group B streptococci & 38 \\
Enterococci & 34 \\
a-Streptococci & 32 \\
Other Enterobacteriaceae & 15 \\
Candida albicans & 15 \\
Staphylococcus aureus & 13 \\
\hline
\end{tabular}

Managing skin wetness is the key factor in preventing dermatitis. The disrupted structure of the SC, resulting from overhydration, leads to enhanced permeability and increased susceptibility to irritants [36]. Water itself may also be a skin irritant. It has been shown that occlusion of skin with water-soaked patches can induce inflammation in the skin [37]. Overhydrated skin is also subjected to major mechanical effects, wet skin having a significantly higher frictional coefficient than dry skin [38]. At higher moisture levels, there is also an increased activity and growth of microorganisms [39].

An important method for the treatment of DD and IAD is to establish a healing environment for the skin [26, 27, 40]. This is accomplished by protecting the skin from further exposure to irritants and by minimizing the exposure to moisture. Evidently, harsh cleansing products and procedures should be avoided and barrier creams and zinc creams could be used to further protect the skin. If those measures fail, topical corticosteroids or antimicrobials may be used for more severe cases $[26,30]$.

\section{ALLERGIC CONTACT DERMATITIS}

Although most cases of dermatitis in the diaper region of adults and babies are of an irritant nature, there are also cases of allergic contact dermatitis (ACD) [41-45]. ACD is an inflammatory reaction in the skin that follows percutaneous absorption of haptens from the skin surface and recruitment of previously sensitized, antigen-specific $\mathrm{T}$ lymphocytes to the skin. ACD is the clinical manifestation of a contact allergy that one develops in contact with small, reactive chemicals. Lifelong sensitization will mount an immune response upon renewed contact with the allergen [46]. Groups of chemicals frequently causing contact allergy are listed in Table 2 [47].

The materials in an absorbent hygiene product mainly consist of polymeric compounds, which are too large to penetrate the skin and thus cannot cause contact allergies. When adding, e.g., skin care compounds to the product, it is important to bear in mind the safety aspects and the risk of introducing allergenic compounds. Fragrances, dyestuff and skin care ingredients are often small and sometimes reactive chemicals that potentially could induce contact allergy. Several cases of diaper dye dermatitis have been reported [48]. It is important to be extra careful when choosing materials and additives for these kinds of products, since they are worn on skin areas of high absorption (genitals), and the occlusion of the absorbent product further enhances skin penetration.

Table 2 Examples of compounds causing allergic contact dermatitis [47]

Examples of compounds frequently causing allergic contact dermatitis

Fragrances (e.g. eugenol, cinnamal)

Metal compounds (e.g. nickel and chromium)

Preservatives (e.g. $\mathrm{MCI} / \mathrm{MI}^{\mathrm{a}}$, formaldehyde)

Topical drugs (e.g. local anaesthetics and antibiotics)

Rubber chemicals (e.g. thiuram compounds)

Plants (e.g. compositae plants)

Plastic- and glue chemicals (e.g. acrylics and epoxy compounds)

Textile- and hair dyes (e.g. PPD ${ }^{\mathrm{b}}$, toluene-2,5-diamine)

a $M C I / M I$ Methylchloro- and methylisothiazolinone

b PPD Para-phenylenediamine 
Until recently, ACD has been considered to be uncommon in children due to a belief that children are less exposed to contact allergens and that their immune system is not fully developed and therefore less susceptible [49-51]. ACD in children may be more prevalent than previously known, and patch testing in children with dermatitis has revealed positive reactions in $15-52 \%$ of subjects. Children as young as 6 months of age have been found to be sensitized, and case reports have documented ACD among children as young as 1 week of age $[50,52-55]$. In old age, there is a decrease in cutaneous immune function which, e.g., leads to increased bacterial and fungal infections as well as cutaneous malignancies. There have been studies indicating that old subjects also have a reduced ability to mount ACD reactions in the skin [56]. The ability to become sensitized is also diminished in old age [57]. On the other hand, older persons are more likely to have become sensitized to more contact allergens than younger subjects [58].

As recommended by Smith et al. [59], if a diaper dermatitis (or IAD) fails to improve, by means of, e.g., frequent diaper changes and use of emollients, ACD should be considered and epicutaneous patch testing conducted. Importantly, not only the chemical constituents of the diaper/incontinence product but also skin care products and wipes used in the diaper area should be looked at. Suppliers should be asked to provide the different materials of interest to help in identifying the potential allergen(s).

\section{THE VULNERABLE SKIN OF USERS OF ABSORBENT HYGIENE PRODUCTS}

Besides the stress that is put on the skin from the exposure to urine and faeces, and the constant covering of the skin by an absorbent product, most of the users of absorbent hygiene products are either very young or old. Both young and aged skins are, in different ways, extra vulnerable to external insults. The absorbent hygiene products also cover mucosa, which lacks the barrier properties of keratinized skin.

\section{THE BABY SKIN}

The skin of the newborn is reported to be $40-60 \%$ thinner than adult skin, affecting all skin layers [60]. Precise measurements of skin layer thicknesses are elusive, but in a recent study by Stamatas and coworkers [61], the infant epidermis (3-24 months old) and the SC were reported to be $20 \%$ and $30 \%$ thinner, respectively, than found in adults. A thin SC in combination with an up to five times larger body-surface-to-weight ratio of the newborn $[62,63]$ increases the risk for skin damage, percutaneous infection and percutaneous toxicity from topically applied agents [62, 64].

The adaption of the skin barrier to the new conditions after birth, in the dry and more temperature-changing environment outside the uterus, was formerly thought to be ready shortly after birth [65-67]. Despite this, an increased tendency to develop ICD and ACD [68-70,] and an increased percutaneous absorption than for adults have been reported, which suggests that the skin barrier is still under development after birth $[65,71,72]$. In a study by Nikolovski et al. [73] it was shown that, even if infant SC seemed intact shortly after birth, the storage and transportation of water in infant SC (3-12 month of age) were different from adult skin at least during the first year of life. Infant SC has also been shown to be more hydrated and to contain less natural moisturizing factors than adult skin. They conclude that the infant skin barrier should not be looked at as being deficient at birth, but that there is an ongoing process of optimization that balances growth, thermoregulation, water barrier and protective functions which continues to at least 1 year of age. In a study by Mack et al. [74], it was found that water-holding and transport properties in the skin of children are different from adults up to the age of 4 years.

The corneocytes of the infant have been shown to be both smaller in size [61] and thicker in height than for the adult [75], which has been explained by the higher turnover rates of keratinocytes found in children under 1 year of age [61]. The increased cell turnover rates may result in an increased number of 
incompletely matured cells and thus negatively affect the functionality of the skin barrier [76]. Since infant SC is thinner [61], the number of corneocyte layers in the infant SC is also reduced [77], which may further explain the increased sensitivity and propensity of developing, e.g., DD.

\section{AGED SKIN}

Like all organs, skin ages with progressive morphologic and physiologic changes over time, which is the result of a genetic program combined with cumulative damage to genes and proteins. There are two types of skin aging: chronological, or intrinsic, skin aging, and photoaging, or extrinsic, skin aging. The former is related to intrinsic factors such as genetics and changes in the endocrine environment, and the latter is caused by environmental factors, with UV radiation and tobacco smoking being by far the most important [78]. Naturally, regarding aging of the skin in body areas relevant to the use of incontinence products, intrinsic skin aging is the dominant type.

Intrinsically aged skin is characterized by several morphological changes leading to deterioration of many skin functions [78, 79]. Thinning of the epidermis leads to increased vulnerability of the skin. A decrease in mitotic activity together with an increased duration of cell cycle and migration time results, e.g., in delayed wound healing. A slow replacement of barrier lipids, which are important for the skin barrier function, consequently results in a disturbed barrier function. Flattening of the dermo-epidermal junction, resulting in a smaller surface between the epidermis and the dermis, means less communication and reduced nutrient transfer between the layers. This also produces a higher sensitivity to mechanical damage. Reduction of dermis thickness due to a decrease number of fibroblasts, collagen fibers and elastic fibers lead to reduced strength and elasticity. The reduction of cutaneous microvasculature gives disturbed thermoregulation and supply of nutrients, while a reduction of nerve endings leads to disturbed sensory function. As mentioned earlier, in older humans, there is also a defective immunity in the skin. Clinically, intrinsically aged skin appears dry and pale with fine wrinkles and laxity [80].

It is also easy to understand the link between old age and the development of pressure ulcers. There is an association between IAD and pressure ulcers, with evidence that IAD increases the risk for pressure ulcer development [81]. Both moisture and friction/shear (in addition to ischemia, sensory perception, activity, mobility and nutrition) are risk factors for the development of pressure ulcers, and links IAD to pressure ulcer development. In addition, there is difficulty in differentiating superficial pressure ulcers from mild to moderate IAD, since they both present as erythema of intact skin. The underlying etiologic factors, however, differ where the erythema associated with a superficial pressure ulcer comes from an inflammatory response to ischemic damage in subdermal tissues, while in IAD the erythema results from an inflammatory response to irritant exposure restricted to the epidermis and dermis. The skin lesions are also present in slightly different locations: pressure ulcers over bony prominences, and IAD mostly in the perianal area, on inner thighs and on the buttocks. Another difference is that erythema associated with a pressure ulcer is non-blanchable [81]. If the precise cause is known, a successful therapy may more easily be selected.

\section{MUCOSA}

Mucosa is defined as a non-keratinized epithelium. The vulvar region in the genital area of females is a body location where both keratinized and non-keratinized skin co-exists. Generally, the outermost parts of the vulvar area consist of normal, keratinized skin, while the inner regions consist of non-keratinized epithelium. Between those areas, the epidermis is thinner and a gradual decrease in keratinization is seen [82]. Accordingly, the "border areas" are known to be more permeable to exogenous substances, more prone to irritant reactions, and to have a unique microbial ecology [83]. The mucous epithelium consists of loosely held, 
large, non-keratinized cells. In comparison to the well-organized and keratinized SC, the superficial layer of the mucosa also contains less packed layers and a less organized lipid structure [82]. This results in increased permeability (about 3-4 times higher than keratinized skin) and makes the skin more prone to irritant reactivity $[83,84]$.

The morphology and physiology of the vulva and vagina change over a lifetime, and the most prominent changes are connected to puberty, menstrual cycle, pregnancy and menopause [84]. Dermatitis in the perineum, the vulva and on the buttocks is a well-recognized and significant problem among incontinent elderly women [85].

\section{SKIN CARE OF THE DIAPER AREA}

Given the stress that is put on the skin under a diaper or an absorbent incontinence product, from urine and faeces as well as from the changes in the microclimate, it is easily understood that the skin in that region of the body is more vulnerable and needs extra care. This is even more evident in the developing skin of babies and in elderly skin with diminished functions. Cleansing products can interfere with the process of DD and IAD by the removal of skin contaminants and irritants. Cleansers should preferably contain mild surfactants (non-ionic) instead of soaps or more harsh surfactants (anionic) [86]. An emulsion cleanser, containing both a water phase and an oily, emollient phase, can offer even more advantages by mildly cleansing the skin but also caring for the skin, like a lotion. A no-rinse emulsion cleanser has been shown to cleanse the skin as effectively (in terms of the number of residual bacteria left on the skin) as soap and water [87]. Wipes can be used to cleanse the skin and are a convenient solution in some situations. Wipes (free from alcohol, fragrance, essential oils and harsh detergents) have been shown to be equivalent in terms of mildness to the skin compared to cleansing with water and cotton wool [88], and might therefore be a good alternative. Kottner et al. [89] has recently systematically reviewed the existing evidence for the effectiveness of skin care interventions for promoting and maintaining skin integrity and skin barrier function in the aged. The findings in that review were limited due to design and reporting weaknesses of the original studies. It could, however, be found that the use of emollient soap, non-detergent no-rinse cleansers and cleansers containing low-irritating surfactants showed skin-protecting effects compared to standard care. The skin-protecting effects might be enhanced when emollients and/or barrier products are additionally applied.

For babies, water and a washcloth are sufficient in most situations, but appropriately formulated cleansers could also be used. Emollients could be used if needed to maintain or enhance skin barrier function $[90,91]$.

For all wearers of absorbent hygiene products, a holistic approach of using high-quality absorbent hygiene products in combination with appropriate skin care will help to maintain good skin health.

\section{ACKNOWLEDGEMENTS}

No funding was received for the preparation of this review. Article processing charges were funded by SCA Hygiene Products AB. All named authors meet the International Committee of Medical Journal Editors (ICMJE) criteria for authorship for this manuscript, take responsibility for the integrity of the work as a whole, and have given final approval for the version to be published.

Disclosures. Jan Faergemann is a consultant in ethical and safety questions for various projects at SCA Hygiene Products. Johanna Karlsson Bender is employed by SCA Hygeine Products. Maria Sköld is employed by SCA Hygiene Products.

Compliance with Ethics Guidelines. This article is based on previously conducted studies and does not involve any new studies of human or animal subjects performed by any of the authors.

Data Availability. Data sharing is not applicable to this article as no datasets were generated or analyzed during the current study. 
Open Access. This article is distributed under the terms of the Creative Commons Attribution-NonCommercial 4.0 International License (http://creativecommons.org/licenses/ by-nc/4.0/), which permits any noncommercial use, distribution, and reproduction in any medium, provided you give appropriate credit to the original author(s) and the source, provide a link to the Creative Commons license, and indicate if changes were made.

\section{REFERENCES}

1. Davis JA, Leyden JJ, Grove GL, Raynor WJ. Comparison of disposable diapers with fluff absorbent and fluff plus absorbent polymers: effects on skin hydration, skin $\mathrm{pH}$, and diaper dermatitis. Pediatr Dermatol. 1989;6(2):102-8.

2. Wilson PA, Dallas MJ. Diaper performance: maintenance of healthy skin. Pediatr Dermatol. 1990;7(3):179-84.

3. Oranje AP, de Waard-van der Spek FB. Comparison of cloth and superabsorbent paper diapers for preventing diaper dermatitis. Eur J Pediat Dermatol. 1991;1:225-32.

4. Aly R, Shirley C, Cunico B, Maibach HI. Effect of prolonged occlusion on the microbial flora, $\mathrm{pH}$, carbon dioxide and transepidermal water loss on human skin. J Invest Dermatol. 1978;71(6):378-81.

5. Grove GL, Lemmen JT, Garafalo M, Akin FJ. Assessment of skin hydration caused by diapers and incontinence articles. Curr Probl Dermatol. 1998;26:183-95.

6. Schafer P, Bewick-Sonntag C, Capri MG, Berardesca E. Physiological changes in skin barrier function in relation to occlusion level, exposure time and climatic conditions. Skin Pharmacol Appl Skin Physiol. 2002;15(1):7-19.

7. EDANA sustainability report 2007/2008: Absorbent hygiene products. EDANA international association serving the nonwovens and related industries, Brussels, Belgium. http://www.edana.org/industryinitiatives/sustainability. Accessed 27 June 2017.

8. Elias PM, Friend DS. The permeability barrier in mammalian epidermis. J Cell Biol. 1975;65(1):180-91.

9. van Smeden J, Janssens M, Gooris GS, Bouwstra JA. The important role of stratum corneum lipids for the cutaneous barrier function. Biochem Biophys Acta. 2014;1841(3):295-313.

10. Elias PM. Epidermal lipids, barrier function, and desquamation. J Invest Dermatol. 1983;80(1 Suppl):44s-9s.

11. Swartzendruber DC, Wertz PW, Madison KC, Downing DT. Evidence that the corneocyte has a chemically bound lipid envelope. J Invest Dermatol. 1987;88(6):709-13.

12. Michaels AS, Chandrasekaran SK, Shaw JE. Drug permeation through human skin: theory and in vitro experimental measurement. AIChE. 1975;21(5):985-96.

13. Forslind $\mathrm{B}$. The structure of the human skin barrier. In: Kanewa L, Elsner P, Wahlberg JE, Maibach HI, editors. Handbook of occupational dermatology. Berlin: Springer; 2000. p. 56-63.

14. Bouwstra JA, Gooris GS, van der Spek JA, Bras W. Structural investigations of human stratum corneum by small-angle X-ray scattering. J Invest Dermatol. 1991;97(6):1005-12.

15. Norlen L, Al-Amoudi A, Dubochet J. A cryotransmission electron microscopy study of skin barrier formation. J Invest Dermatol. 2003;120(4):555-60.

16. Iwai I, Han H, den Hollander L, Svensson S, Ofverstedt LG, Anwar J, et al. The human skin barrier is organized as stacked bilayers of fully extended ceramides with cholesterol molecules associated with the ceramide sphingoid moiety. J Invest Dermatol. 2012;132(9):2215-25.

17. Houben E, De Paepe K, Rogiers V. A keratinocyte's course of life. Skin Pharmacol Physiol. $2007 ; 20(3): 122-32$.

18. Rippke FVS, Schwanitz HJ. The acidic milieu of the horny layer. New findings ont he physiology of skin pH. Am J Clin Dermatol. 2002;3(4):261-72.

19. Ali SM. Skin pH: from basic science to basic skin care. Acta Derm Venereol. 2013;93:261-7.

20. Elias PM. The how, why and clinical importance of stratum corneum acidification. Exp Dermatol. 2017. doi:10.1111/exd.13329 (Epub ahead of print).

21. Schreml S, Zeller V, Meier RJ, Kortinng HC, Behm B, Landthaler $\mathrm{M}$, et al. Impact of age and body site on adult female skin surface $\mathrm{pH}$. Dermatology. 2012;224:66-71.

22. Matousek JL, Campbell KL. A comparative reveiw of cutaneous pH. Vet Dermatol. 2002;13:293-300. 
23. Shin HT. Diaaper dermatitis that does not quit. Dermatol Ther. 2005;18:124-35.

24. Prasad HRY, Srivastava P, Verma KK. Diaper dermatitis-an overview. Indian J Pediatr. 2003;70:635-7.

25. Scheinfeld N. Diaper dermatitis. A review and brief survey of eruptions of the diaper area. Am J Clin Dermatol. 2005;6(5):273-81.

26. Stamatas GN, Tierney NK. Diaper dermatitis: etiology, manifestations, prevention, and management. Pediatr Dermatol. 2014;31(1):1-7.

27. Gray M, Beeckman D, Bliss DZ, Fader M, Logan S, Junkin J, et al. Incontinence-associated dermatitis: a comprehensive review and update. J Wound Ostomy Continence Nurs. 2012;39(1):61-74.

28. Gray M. Optimal management of incontinence-associated dermatitis in the elderly. Am J Clin Dermatol. 2010;11(3):201-10.

29. Beeckman D, Woodward S, Gray M. Incontinence-associated dermatitis: step by step prevention and treatment. $\mathrm{Br} \mathrm{J}$ Community Nurs. 2011;16(8):382-9.

30. Gray M. Incontinence-related skin damage: essential knowledge. Ostomy Wound Manag. 2007;53(12):28-32.

31. Adalat S, Wall D, Goodyear H. Diaper dermatitis-frequency and contributory factors in hospital attending children. Pediatr Dermatol. 2007;24(5):438-88.

32. Liu N, Wang X, Odio M. Frequency and severity of diaper dermatitis with use of traditional chinese cloth diapers: observations in 3- to 9-month-old children. Pediatr Dermatol. 2011;28(4):380-6.

33. Blume-Peytavi U, Hauser M, Lunneman L, Stamatas GN, Kottner J, Garcia Bartels N. Prevention of diaper dermatitis in infants-a literature review. Pediatr Dermatol. 2014;31(4):413-29.

34. Runeman B, Rybo G, Forsgren-Brusk U, Larkö O, Larsson P, Faergemann J. The vulvar skin microenvironment: influence of different panty liners on temperature, $\mathrm{pH}$ and microflora. Acta Derm Venereol. 2004;84(4):277-84.

35. Stamatas GN, Zerweck C, Grove G, Martin KM. Documentation of impaired epidermal barrier in mild and moderate diaper dermatitis in vivo using noninvasive methods. Pediatr Dermatol. 2011;28(2):99-107.

36. Zhai H, Maibach HI. Occlusion vs. skin barrier function. Skin Res Technol. 2002;8:1-6.
37. Tsai T-F, Maibach HI. How irritant is mater? An overview. Contact Dermatitis. 1999;41:311-4.

38. Gerhardt L-C, Strässle V, Lenz A, Spencer ND, Derler $S$. Influence of epidermal hydration on the friction of human skin against textiles. J R Soc Interface. 2008;5:1317-28.

39. Wilson M. Microbial Inhabitants of humans: their ecology and role in health and disease. Cambridge: Cambridge University Press, 2005.

40. Runeman B. Skin interaction with absorbent hygiene products. Clin Dermatol. 2008;26:45-51.

41. Roul S, Ducombs G, Leaute-Labreze C, Taieb A. 'Lucky luke' contact dermatitis due to rubber components of diapers. Contact Dermatitis. 1998;38:363-4.

42. Onken AT, Baumstark J, Belloni B, Ring J, Schnopp C. Atypical diaper dermatitis: contact allergy to mercapto compounds. Pediatr Dermatol. 2011;28(6):739-41.

43. Belhadjali H, Giordano-Labadie F, Rance F, Bazex J. 'Lucky Luke' contact dermatits from diapers: a new allergen? Contact Dermatitis. 2001;44:248.

44. Giroux L, Pratt MD. Contact dermatitis to incontinency pads in a (meth)acrylate allergic patient. American Journal of Contact Dermatitis. 2002; 13(3):143-5.

45. JiaDe Y, Treat J, Chaney K, Brod B. Potential allergens in disposable diaper wipes, topical diaper preparations, and disposable diapers: under-recognized etiology of pediatric perineal dermatitis. Dermatitis. 2016;27(3):110-8.

46. Scheynius A. Immunological aspects. In: Lepoittevin JP, Basketter DA, Goossens A, Karlberg AT, editors. Allergic contact dermatitis The molecular basis. Berlin: Springer; 1998. p. 4-18.

47. Andersen KE, White IR, Goossens A. Allergens from the European Baseline series. In: Johansen JD, Frosch PJ, Lepoittevin J-P, editors. Contact Dermatitis. 5th ed. Berlin: Springer; 2011. p. 545-90.

48. Alberta L, Sweeney SM, Wiss K. Diaper dye dermatitis. Pediatrics. 2005;116(3):450-2.

49. Kutting B, Brehler R, Traupe H. Allergic contact dermatitis in children: strategies of prevention and risk management. Eur J Dermatol. 2004;14(2):80-5.

50. Bruckner AL, Weston WL, Morelli JG. Does sensitization to contact allergens begin in infancy? Pediatrics. 2000;105(1):e3.

51. Militello G, Jacob SE, Crawford GH. Allergic contact dermatitis in children. Curr Opin Pediatr. 2006;18(4):385-90. 
52. Weston WL, Bruckner A. Allergic contact dermatitis. Pediatr Clin North Am. 2000;47(4):897-900.

53. Fischer AA. Allergic contact dermatitis in early infancy. Cutis. 1994;54:300-2.

54. Ayala F, Balato N, Lembo G, Patruno C, Tosti A, Schena D, et al. A multicentre study of contact sensitization in children. Gruppo Italiano Ricerca Dermatiti da Contatto e Ambientali (GIRDCA). Contact Dermatitis. 1992;26(5):307-10.

55. Lembo S, Lembo C, Patruno C, Cuomo P, Ayala F, Balato $\mathrm{N}$, et al. Contact sensitization of children referred to the Dermatology Department of the University Federico II of Naples, Italy: a two-decade years history. Giornale italiano di dermatologia e venereologia: organo ufficiale, Societa italiana di Dermatologia e Sifilografia. 2017.

56. Vukmanovic-Stejic M, Rustin MHA, Nikolich-Zugich J, Akbar AN. Immune responses in the skin in old age. Curr Opin Immunol. 2011;23:525-31.

57. Friedmann PS, Pickard C. Contact hypersemsitivity: quantitative aspects, susceptibility and risk factors. In: Martin SF, editor. T Lymphocytes as Tools in Diagnostics and Immunotoxicology. Basel: Springer; 2014. p. 51-71.

58. Warshaw EM, Raju SI, Fowler JF, Maibach HI, Belsito DV, ZK A, et al. Positive patch test reactions in older individuals: retrspective analysis from the North American Contact Dermatitis Group, 1994-2008. J Am Acad Dermatol. 2012;66(2):229-40.

59. Smith WJ, Jacob SE. The role of allergic contact dermatitis in diaper dermatitis. Pediatr Dermatol. 2009;26(3):369-70.

60. Siegfried EC. Neonatal skin care and toxicology. In: Eichenfield LF, Frieden IJ, Esterly NB, editors. Textbook of neonatal dermatology. Philadelphia: Saunders; 2001. p. 62-72.

61. Stamatas GN, Nikolovski J, Luedtke MA, Kollias N, Wiegand BC. Infant skin microstructure assessed in vivo differs from adult skin in organization and at the cellular level. Pediatr Dermatol. 2010;27(2):125-31.

62. Bertaux E, Derler S, Rossi RM. Xianyi Zeng, Koehl L, Ventenat V. Textile, Physiological, and Sensorial Parameters in Sock Comfort. Text Res J. 2010;80(17):1803-10.

63. West DP, Worobec S, Solomon LM. Pharmacology and toxicology of infant skin. J Invest Dermatol. 1981;76(3):147-50.
64. Mancini AJ. Skin. Pediatrics. 2004;113(4 Suppl):1114-9.

65. Harpin VA, Rutter N. Barrier properties of the newborn infant's skin. J Pediatrics. 1983;102(3):419-25.

66. Kalia YN, Nonato LB, Lund CH, Guy RH. Development of skin barrier function in premature infants. J Invest Dermatol. 1998;111(2):320-6.

67. Visscher MO, Chatterjee R, Munson KA, Pickens WL, Hoath SB. Changes in diapered and nondiapered infant skin over the first month of life. Pediatr Dermatol. 2000;17(1):45-51.

68. Berg RW, Milligan MC, Sarbaugh FC. Association of skin wetness and $\mathrm{pH}$ with diaper dermatitis. Pediatr Dermatol. 1994;11(1):18-20.

69. Seidenari S, Giusti G. Objective assessment of the skin of children affected by atopic dermatitis: a study of $\mathrm{pH}$, capacitance and TEWL in eczematous and clinically uninvolved skin. Acta Derm Venereol. 1995;75(6):429-33.

70. Wilhelm KP, Maibach HI. Factors predisposing to cutaneous irritation. Dermatol Clin. 1990;8(1):17-22.

71. Behne MJ, Barry NP, Hanson KM, Aronchik I, Clegg RW, Gratton E, et al. Neonatal development of the stratum corneum $\mathrm{pH}$ gradient: localization and mechanisms leading to emergence of optimal barrier function. J Invest Dermatol. 2003;120(6):998-1006.

72. Rutter N. Clinical consequences of an immature barrier. Seminars in neonatology. 2000;5(4):281-7.

73. Nikolovski J, Stamatas GN, Kollias N, Wiegand BC. Barrier function and water-holding and transport properties of infant stratum corneum are different from adult and continue to develop through the first year of life. J Invest Dermatol. 2008;128(7):1728-36.

74. Mack MC, Chu MR, Tierney NK, Ruvolo E, Stamatas GN, Kollias N, et al. Water-holding and transport properties of skin stratum corneum of infants and toddlers are different from those of adults: studies in three geographical regions and four ethnic groups. Pediatr Dermatol. 2016;33(3):275-82.

75. Kashibuchi N, Hirai Y, O'Goshi K, Tagami H. Three-dimensional analyses of individual corneocytes with atomic force microscope: morphological changes related to age, location and to the pathologic skin conditions. Skin Res Technol. 2002;8(4):203-11. 
76. Michel S, Schmidt R, Shroot B, Reichert U. Morphological and biochemical characterization of the cornified envelopes from human epidermal keratinocytes of different origin. J Invest Dermatol. 1988;91(1):11-5.

77. Fluhr JW, Lachmann N, Baudouin C, Msika P, Darlenski R, De Belilovsky C, et al. Development and Organization of Human Stratum Corneum After Birth. Electron Microscopy Isotropy Score and Immunocytochemical Corneocyte Labelling as Epidermal Maturation's Markers in Infancy. Br J Dermatol. 2014;171(5):978-86.

78. Yaar M, Gilchrest BA. Skin aging: postulated mechanisms and consequent changes in structure and function. Clin Geriatr Med. 2001;17(4):617-30.

79. Zouboulis CC, Makrantonaki E. Clinical aspects and molecular diagnostics of skin aging. Clin Dermatol. 2011;29:3-14.

80. Hashizume H. Skin aging and dry skin. J Dermatol. 2004;31:603-9.

81. Doughty D, Junkin J, Kurz P, Selekov J, Gray M, Fader $\mathrm{M}$, et al. Incontinece-associated dermatitis. Consensus statements, evidence-based guidelines for prevention and treatment, and current challenges. J Wound Ostomy Continence Nurs. 2012;39(3):303-15.

82. Farage M, Maibach HI. The vulvar epithelium differs from the skin: implications for cutaneous testing to address topical vulvar exposures. Contact Dermatitis. 2004;51(4):201-9.

83. Elsner P. Anatomical and physiological basis of topical therapy of the mucosa. Curr Probl Dermatol. 2011;40:1-8.
84. Farage MA, Maibach HI. Morphology and physiological changes of genital skin and mucosa. Curr Probl Dermatol. 2011;40:9-19.

85. Farage MA, Miller KW, Berardesca E, Maibach HI. Incontinence in the aged: contact dermatitis and other cutaneous consequences. Contact Dermatitis. 2007;57(4):211-7.

86. Telofski LS, Morello AP III, Mack Correa MC, Stamatas GN. The infant skin barrier: can we preserve, protect, and enhance the barrier? Dermatology Res Practice. 2012. doi:10.1155/2012/198789.

87. Rönner AC, Berland CR, Runeman B, Kaijser B. The hygienic effectiveness of 2 different skin cleansing procedures. J Wound Ostomy Continence Nurs. 2010;37(3):260-4.

88. Lavender T, Furber C, Campbell M, Victor S, Roberts I, Bedwell C, et al. Effect on skin hydration of using baby wipes to clean the napkin area of newborn babies: assessor-blinded randomised controlled equivalence trial. BMC Pediatr. 2012. doi:10.1186/ 471-2431-12-59.

89. Kottner J, Lichterfeld A, Blume-Peytavi U. Maintaining skin integrity in the aged: a systematic review. Br J Dermatol. 2013;169:528-42.

90. Ness MJ, Davies DMR, Carey WA. Neonatal skin care: a concise review. Int $\mathrm{J}$ Dermatol. 2013;52:14-22.

91. Blume-Peytavi U, Lavender T, Jenerowicz D, Ryumin I, Stalder J-F, Torrelo A, et al. Recommendations from a Europena roundtable meeting on best practice healthy infant skin care. Pediatr Dermatol. 2016;33(3):311-21. 